\title{
A structure-based design of new C2-and C13-substituted taxanes: Tubulin binding affinities and extended quantitative structure-activity relationships using comparative binding energy (COMBINE) analysis
}

Claire Coderch, ${ }^{1}$ Yong Tang, ${ }^{2}$ Javier Klett, ${ }^{3}$ Shu-En Zhang, ${ }^{2}$ Yun-Tao Ma, ${ }^{2}$ Wang Shaorong, ${ }^{2}$ Antonio Morreale, ${ }^{2}$ Ruth Matesanz, ${ }^{4}$ Benet Pera, ${ }^{4}$ Angeles Canales, ${ }^{4}$ Jesús Jiménez-Barbero, ${ }^{4}$ José-Fernando Díaz, ${ }^{4}$ Wei-Shuo Fang, ${ }^{3}$ and Federico Gago ${ }^{1} *$

${ }^{1}$ Departamento de Farmacología, Universidad de Alcalá, E-28871 Alcalá de Henares, Madrid, Spain - Unidad Asociada Instituto de Química Médica CSIC.

${ }^{2}$ State Key Laboratory of Bioactive Substances and Functions of Natural Medicines, Institute of Materia Medica, Chinese Academy of Medical Sciences \& Peking Union Medical College, 2A Nan Wei Road, Beijing 100050, P. R. China.

${ }^{3}$ Unidad de Bioinformática, Centro de Biología Molecular Severo Ochoa (CSIC/UAM), Campus UAM, Cantoblanco, E-28049 Madrid, Spain.

${ }^{4}$ Centro de Investigaciones Biológicas, Consejo Superior de Investigaciones Científicas, Campus Complutense UCM, E-28040 Madrid, Spain.

* Address correspondence to either author: wfang@imm.ac.cn or federico.gago@uah.es.

KEYWORDS: Paclitaxel; taxanes; anticancer agents; tubulin; microtubules; molecular dynamics simulations; structure-activity relationships.

\section{ABSTRACT}


Molecular models were built for the complexes of $\beta$-tubulin with 47 taxanes for which binding free energies have been experimentally measured. Residue-based ligand-receptor interaction energies were calculated in each complex, as well as the electrostatic contributions to the desolvation of both ligand and receptor. By assigning weights to a selection of these energy terms, a projection to latent structures regression method (COMBINE) succeeded in providing a good prediction of the binding affinities for all but three compounds. The fact that these three outliers display large unfavorable entropic contributions to the binding free energies highlights a limitation of this approximation and may attest to the importance of taxane preorganization for tubulin binding, a possibility that is in good accord with results from NMR data and molecular dynamics simulations. Ten novel taxanes bearing modifications at the $\mathrm{C} 2$ and $\mathrm{C} 13$ positions of the baccatin core were then synthesized and tested for external validation and model updating. The tubulin-binding affinity of one of the novel taxanes was higher than that of docetaxel. The expanded COMBINE model for 54 taxanes conserved its robustness and yielded receptor-based quantitative structure-activity relationships that shed additional light on the determinants of tubulin-binding affinity for this class of antitumor agents and pave the way to further structural modifications.

\section{INTRODUCTION}

Paclitaxel (PXL, a.k.a. Taxol ${ }^{\oplus}$ ) was originally discovered in the bark of the Pacific yew tree (Taxus brevifolia) and found to promote the assembly of microtubules (MT) by preventing tubulin depolymerization in dividing mammalian cells. ${ }^{1}$ This increased MT stability results in the inhibition of the normal dynamic reorganization of the microtubular network that is essential for vital interphase and mitotic cellular functions. In clinical use since 1992, PXL became a first-in- 
class anti-mitotic drug that is currently indicated in the chemotherapy of a variety of human tumors including ovarian, breast and non-small cell lung carcinomas. Notwithstanding the remarkable potency of this antineoplastic agent, its limited availability from its natural source, its poor aqueous solubility and the emergence of resistance in cancer cells, partly due to overexpression of multidrug efflux transporters, ${ }^{2}$ made it desirable from the start to obtain new analogues (taxanes) more readily and with an improved pharmacological profile. ${ }^{3-7}$ This goal has been partially achieved with the clinical development and marketing of the semisynthetic derivatives docetaxel (DXL, Taxotere $\left.{ }^{\circledast}\right)$ and, more recently, cabazitaxel (Jevtana $\left.{ }^{\circledast}\right)$, both of which partially overcome some of PXL's limitations. Nevertheless, structure-based design efforts in the search for novel taxanes ${ }^{8}$ were hampered for many years because of difficulties associated with tubulin crystallization, the low affinity of PXL for unpolymerized tubulin subunits and the poor water solubility of the drug. ${ }^{9}$

The first reliable three-dimensional model of tubulin in atomic detail was reported in $1998 .{ }^{10}$ This long sought-after structure, deposited in the Protein Data Bank (PDB) as entry 1TUB, was obtained by electron crystallography of zinc-induced sheets of bovine tubulin bound to PXL. At this point it became clear that PXL binds to the lumenal side of the $\beta$ subunit in the $\alpha, \beta$-tubulin heterodimer. Subsequent refinement improved the resolution to $3.5 \AA$ (PDB entry $1 \mathrm{JFF})^{11}$ but neither the acidic C-terminal tails nor the N-terminal loop including residues 35-60 in the $\alpha$ subunit could still be traced accurately. Moreover, due to the limited certainty about side-chain orientation for many residues at the taxane-binding site (and elsewhere), the precise set of interactions between $\beta$-tubulin and bound $\mathrm{PXL}^{12}$ (and related taxanes or other ligands such as the epothilones $)^{13}$ could not be entirely clarified from this structure.

The initial pharmacophore that was established for taxanes based on the so-called T-Taxol binding conformation ${ }^{13-16}$ has been the foundation for several structure-guided modifications ${ }^{17,18}$ 
and structure-activity relationship (SAR) studies. ${ }^{6,15,19,20}$ Recent collaborative work from our laboratories resulted in the report of an extended series of 44 semisynthetic taxanes (CTX), which have in common the baccatin core present in PXL, DXL and cephalomannine (CPH) but additionally incorporate a variety of changes at positions $\mathrm{C} 2, \mathrm{C} 7, \mathrm{C} 10$ and $\mathrm{C} 13 .{ }^{21}$ A corollary of this endeavor was the finding of an optimal combination of substituents that yielded the highaffinity taxane CTX40 (Figure 1), the cytotoxicity of which is unaffected by P-glycoprotein (Pgp) overexpression. Furthermore, the binding of all of these compounds to glutaraldehydestabilized bovine MT was measured and an energy-refined binding mode for PXL, DXL and CTX40 to $\beta$-tubulin was proposed and then explored using molecular dynamics (MD) simulations in explicit solvent. Support for the conformation of bound DXL was provided by the excellent agreement obtained with data acquired from transfer nuclear Overhauser effect spectroscopy (TR-NOESY) measurements using MT-bound DXL. ${ }^{21}$ The thermodynamic characterization of the binding of these taxanes to MT revealed not only a range of $\sim 10$ $\mathrm{kcal} \cdot \mathrm{mol}^{-1}$ in binding free energies $(\Delta \mathrm{G})$ but also distinct enthalpic $(\Delta \mathrm{H})$ and entropic $(-\mathrm{T} \Delta \mathrm{S})$ contributions. The existence of rather large enthalpy/entropy compensations ${ }^{22}$ within this series (Figure 2) ${ }^{21}$ attests to the difficulties that can be encountered when theoretical methods are used to try and rationalize the quantitative SAR (QSAR) for these ligands. ${ }^{23}$

In the following we explore the QSAR for the binding to $\beta$-tubulin of these taxanes using a chemometric tool known as Comparative Binding Energy (COMBINE) analysis, ${ }^{24}$ which was recently implemented in a user-friendly graphical interface (gCOMBINE) and released under a scientific/academic nonprofit and noncommercial license. ${ }^{25}$ We show that robust cross-validated models are produced that correlate the $\Delta \mathrm{G}$ values within the series (with only three exceptions) with a set of weighted selected interactions within the binding site. Additional support is gained for the proposed protonation state of His $229,{ }^{21,26}$ a residue that is shown to play a major role in 
modulating the affinity differences. The QSAR model was then externally challenged and updated with ten novel C2- and C13-modified taxanes that were synthesized and experimentally tested.

\section{RESULTS AND DISCUSSION}

The 47 taxanes studied in our training set span a range of binding energies of $\sim 10 \mathrm{kcal} \cdot \mathrm{mol}^{-1}$ and differ from one another in the nature of the groups attached to the $\mathrm{C} 2, \mathrm{C} 7, \mathrm{C} 10$ and $\mathrm{C} 13$ positions of the common baccatin scaffold (Figure 3). Earlier energy decomposition analyses on a limited set of refined taxane-tubulin complexes highlighted the amino acids that are thought to be key for binding and helped to understand, albeit in a qualitative way, the observed SAR. ${ }^{21}$ When the whole set of complexes was subjected to a COMBINE analysis, the PLS result showed the clearly outlying behavior of CTX42, CTX43 and CTX44. The common characteristic of these taxanes is the presence of an amide linker in the C2 substituent instead of the ester found in their most similar counterparts CTX21, CTX11 and CTX6, respectively. That this sole modification is translated into a largely decreased binding free energy is in stark contrast with the facts that (i) the binding modes appear very similar, and (ii) no protein contacts are apparent in this region that could account for these differences, in contrast to what has already been described for C2 Slinked taxanes. ${ }^{27}$ However, when these three grossly overpredicted compounds were removed from the training set, a robust cross-validated COMBINE model was obtained $\left(\mathrm{r}^{2}=0.94\right.$ and $\mathrm{q}^{2}=0.89$ for the best model; average $\mathrm{r}^{2}=0.94 \pm 0.03$ and $\mathrm{q}^{2}=0.87 \pm 0.02$ for the 10 runs, using $5 \pm 1$ LV). To assess whether the affinity of the most tightly binding compound, CTX40, could have been predicted using the remaining set of analogues and/or whether this molecule was having a high leverage on the model, we left it out and run gCOMBINE with the remaining 43 complexes. The quality of the resulting PLS equation $\left(r^{2}=0.94\right.$ and $\mathrm{q}^{2}=0.86$ for the best model; average 
$\mathrm{r}^{2}=0.94 \pm 0.03$ and $\mathrm{q}^{2}=0.84 \pm 0.02$ for the 10 runs, using $5 \pm 1 \mathrm{LV}$ ) proved to be similar to that obtained previously and the binding free energy of CTX40 was predicted with high accuracy (Figure 4). Of note, the outstanding affinity of CTX40 was also predicted earlier on the basis of additivity of contributions from optimal substituents. ${ }^{21}$

The relative importance of the $\beta$-tubulin residues that best explain the differences in binding free energies, as judged from the assigned PLS pseudocoefficients (Table 1), depends on the actual magnitude of the calculated interaction energies because these signed coefficients are used to properly weigh these terms. ${ }^{24,28}$ Since the energy values are usually negative (i.e. attractive), a positive coefficient will make the calculated binding free energy more negative, and vice versa. Thus, improved van der Waals interactions between the C13 moiety and both Val23 and Asp26 are predicted to result in gains in binding affinity. The same can be said for those established between the baccatin core and the C2 substituent and residues Asp226, His229, Ala233, Phe272 and Leu275. On the contrary, the more the ligands interact with other residues, particularly Cys213, Leu217 and Leu219, the lower the affinity, which most likely reflects the existence of steric clash. ${ }^{28}$

From the electrostatics point of view, the importance of the interactions with His229, $\operatorname{Arg} 278$ and WAT2 is reflected on the positive coefficients assigned to the terms involving these two protein residues and one of the water molecules. In this respect, it is noteworthy that the mutation of Arg278 to Ser is known to confer resistance to PXL. ${ }^{29,30}$ On the other hand, the negative PLS coefficient that modulates the electrostatic contribution to ligand desolvation strongly suggests that this factor plays an important role in the binding affinity differences, in contrast to the small positive coefficient that is assigned to the desolvation of the binding pocket.

These computational studies were undertaken considering a $\mathrm{pH}$ of 6.5 for the calculation of the protonation state of ionizable groups in $\beta$-tubulin to mimic the experimental conditions. ${ }^{21}$ At this 
$\mathrm{pH}$ the side-chain imidazole of His229 (found in the middle of helix 7 and positionally equivalent to Arg229 in $\alpha$-tubulin) is likely to be protonated on both $N \delta$ and $N \varepsilon$ giving rise to (i) a MEP in the taxane-binding site that is quite distinct from that obtained with a neutral imidazole side chain, ${ }^{21}$ and (ii) different hydrogen-bonding possibilities. To consider an alternative scenario, we also refined the whole set of complexes with a $\beta$-tubulin in which His 229 was protonated exclusively on $\mathrm{N} \varepsilon$. The corresponding COMBINE model (Supporting Information Figure S1) turned out to be of inferior quality (average $r^{2}$ and $q^{2}$ over 10 runs of $0.75 \pm 0.02$ and $0.63 \pm 0.02$, respectively, using $2 \pm 1 \mathrm{LV}$ ) and was unable to predict accurately the binding free energy of CTX40 when this compound was taken out of the training set. The largest change in the PLS pseudocoefficients affected precisely the electrostatic interaction energy with His229 (Supporting Information Table S1). From this comparison we surmise that His229 is indeed more likely to be protonated of both imidazole nitrogens.

With a view to expanding the exploration of the taxane-binding pocket and validating our best COMBINE model with some external molecules, ten novel taxanes (CTX55-CTX64, Figure 5) were designed, synthesized and tested (Supporting Information Tables S2 and S3). The rationale for synthesizing CTX55 and CTX56 was to explore the effect of replacing the O-benzoyl (OBz) substituent at the $\mathrm{C} 2$ position with an extended $\mathrm{N}$-containing aromatic ring system (i.e. a quinoline or an isoquinoline, respectively) that might improve the stacking interactions with the imidazole of His229. In taxanes CTX57 to CTX60, one of the methyl groups in the tertbutoxycarbonyl attached to the $\mathrm{NH}$ bonded to $\mathrm{C} 3$ ' on the $\mathrm{C} 13$ substituent ( $3^{\prime} \mathrm{N}$ position) was replaced with a small substituent in an attempt to fill a protein cavity in the vicinity of this moiety. Finally, three different ring systems were attached to $\mathrm{C}^{\prime}$ ' to probe the pocket where the common phenyl ring of taxanes is lodged. Most of these modifications were therefore intended to 
improve the interactions with His229 and other residues to which some of the highest PLS coefficients were assigned in the COMBINE model (Table 1).

The binding affinities of the new analogs were overpredicted to different extents (Figure 6). The calculated $\Delta \mathrm{G}$ values for the taxanes bearing modifications at $\mathrm{C} 2$ and $\mathrm{C} 3$ ', including the most potent CTX63 and CTX64, deviated from the experimental measurements much less than those modified at $3^{\prime} \mathrm{N}$. Of these, CTX59 clearly behaved as an outlier. This result is likely a consequence of the lack of accurate information in the PLS model regarding the protein residues that interact with the $3^{\prime} \mathrm{N}$ substituents because this region was totally unexplored in the original training series. As discussed before, lead optimization is a cyclic process involving repeated rounds of compound design, synthesis and testing, and QSAR models derived at one stage need to be continually updated incorporating as much new information as possible. ${ }^{24}$ To prove this point we added the $3^{\prime} \mathrm{N}$-substituted analogues CTX57-CTX60 to the original training set and tried to predict the affinity of the remaining novel taxanes. This updated model $\left(r^{2}=0.93, q^{2}=0.77\right.$ for the best model and average $r^{2}=0.94 \pm 0.01, q^{2}=0.72 \pm 0.04$ over 10 runs using $6 \pm 1 \mathrm{LV}$ ) was able to predict the binding free energies of CTX55, CTX56 and CTX61 to CTX64 remarkably well (Figure 7). The PLS coefficients barely differed from the original ones except for those assigned to Lys 19 and Glu22 which became larger than before and of opposite signs for the van der Waals and electrostatic terms (Table 2). Finally, when the whole set comprising 54 taxanes was subjected to COMBINE analysis using random groups for cross-validation, similarly good figures of merit $\left(r^{2}=0.94, q^{2}=0.79\right.$ for the best model and average $r^{2}=0.94 \pm 0.01, q^{2}=0.77 \pm 0.2$ over 10 runs using $7 \pm 1 \mathrm{LV}$ ) were obtained (Figure 8) and updated PLS coefficients were assigned (Table 3).

Among the novel taxanes reported herein, CTX63 and CTX64 display binding affinities that are higher than and similar to, respectively, those measured for DXL under identical conditions. 
The better binding affinity reported for CTX63 arises from the favorable hydrogen bonding interaction that the benzylic alcohol at C3' in this ligand establishes with the side-chain carboxylate of Glu27.

Perhaps the most striking feature of our overall results is the outlying behavior (Figure 4) of taxanes CTX42, CTX43, and CTX44, which have in common not only an amide linker instead of an ester between the $\mathrm{C} 2$-substituent and the baccatin core, but also a thermodynamic binding profile that is characterized by a large unfavorable entropic contribution to the Gibbs free energy of binding (Figure 2). It is usually agreed that solvation entropy changes originating from the release of water molecules brought about by the burial of a significant hydrophobic surface are favorable for binding ${ }^{31}$ whereas the loss of conformational degrees of freedom by the inhibitor and/or some residues in the protein is unfavorable. ${ }^{32}$ Thus, a common goal in molecular design is to minimize ligand entropy loss by restraining conformational flexibility and promoting a configuration in the unbound state that optimally matches the binding site, ${ }^{33}$ even though doubts have been cast on this assertion. ${ }^{34}$ This "preorganization" may lead to ligands with affinities in the nanomolar range even in the presence of unfavorable binding enthalpies. ${ }^{35}$ Conversely, favorable binding enthalpies can be largely offset by unfavorable entropic contributions, as clearly seen in the series presented here. In this case, although we have tried to take into account, at least in part, the cost of ligand and binding-site desolvation as well as some water-mediated interactions, we have neglected the configurational entropies of the ligands, the water molecules and the protein. ${ }^{22,34}$ Therefore, we speculated that CTX42, CTX43, and CTX44 might be stabilized in aqueous solution in a conformation that is not compatible with binding to the site. To test this hypothesis, NMR experiments were carried out to characterize the conformation of CTX42, the most water-soluble derivative in both the free and bound states (Supplementary Information Figure S2). In addition, we performed several MD simulations in explicit water to 
sample the conformational space of these amide-containing taxanes and also of CTX40 as a representative example of an ester-containing analog.

The conformation of MT-bound CTX42 was deduced from analysis of TR-NOESY cross peaks. The strong negative cross peaks observed for CTX42 in the presence of MT indicate binding of the taxane to the tubulin preparation (NOESY cross peaks were essentially zero for the free ligand). The fact that the TR-NOESY spectrum of CTX42 in the presence of MT shows an NOE pattern similar to that described for $\mathrm{DXL}^{21}$ points to a similar conformation for both molecules in the bound state. Clear NOEs are observed between the C13 tert-butoxy and C2 aromatic ring protons. The 4-OAc group also gives NOEs with both aromatic rings, and they are stronger with the protons of the phenyl ring on the C13 substituent, which also gives an NOE contact with the methyl group at $\mathrm{C} 12$.

In contrast, no ROE contacts were detected between the C3' tert-butoxy protons and those of the $\mathrm{C} 2$ aromatic ring in the ROESY of free CTX42. Moreover, weak ROEs were observed between the 4-OAc group and the C13 phenyl ring protons whereas no ROEs were observed between this latter moiety and the C12 methyl group. All these data support the hypothesis of different conformations for CTX42 in the free and MT-bound states.

To compare with the NMR data, MD simulations in explicit water were carried out for CTX42, CTX43 and CTX44, as well as for the most potent analog in the whole series (CTX40), whose binding is both enthalpically and entropically favored. The MD trajectories showed that the probabilities of the microstate corresponding to the bound conformation were 0.78 for CTX40 but only $0.0005,0.0001$, and 0.03, respectively, for CTX42, CTX43 and CTX44. Therefore these amide derivatives in aqueous solution appear to be locked in a hydrophobically collapsed conformation that is fully compatible with the ROESY spectrum of free CTX42 and is more energetically favorable than the tubulin-bound conformation by $\sim 6.0 \mathrm{kcal} \cdot \mathrm{mol}^{-1}$ for CTX44 and 
$\sim 4.0 \mathrm{kcal} \cdot \mathrm{mol}^{-1}$ for CTX42 and CTX43 (Supporting Information Figure S3). Collectively, these results support the view that the entropic penalty associated to tubulin binding (Figure 2) may arise from an energetically unfavorable conformational change in the ligand. On the contrary, for taxanes that are preorganized for binding to the site, e.g. CTX40, the ligand-dependent entropic component is likely to be favorable.

Ruth/Fer/Wei, please, paragraph on cytotoxicity.

\section{CONCLUSIONS}

Robust QSAR models have been derived using the COMBINE methodology that support a welldefined orientation for a large series of taxanes within the PXL-binding site of $\beta$-tubulin and highlight the relative importance for binding affinity of a number of protein residues as well as the electrostatic contribution to ligand desolvation. Our results favor the view that His229 is doubly protonated on the imidazole ring and also that some water molecules get trapped in the binding process. When new molecules were synthesized and tested to enrich the chemical diversity of the series and further explore the binding site, we found it necessary to expand the training set to strengthen the predictive ability of the PLS model. A serious limitation was found when it was realized that the affinities of a few analogues whose binding is characterized by a large unfavorable entropic component could not be correlated with the calculated interaction and desolvation energies. To account for this anomalous behavior we hypothesized, on the basis of results from MD simulations in aqueous solution, that the most populated conformation in the free state is unsuitable for binding and is stabilized by hydrophobic collapse. NMR data obtained for the only representative taxane that could be studied tubulin-free in a water-DMSO mixture (CTX42) provided qualitative support to this hypothesis. Given the known additivity of contributions from optimal substituents, ${ }^{21}$ attempts are being made to use this recently acquired 
information to further expand the series and synthesize more analogues that, for example, incorporate the bridging water's hydrogen-bonding functionality into their own structure or a benzylic alcohol in place of a phenyl on C3' in CTX40. The results of this continued effort will be reported in due course.

\section{METHODS}

\section{Theoretical Methods.}

The refined structure of the $\alpha, \beta$-tubulin heterodimer at $3.5 \AA$ resolution (Protein Data Bank code 1JFF) was used for molecular modeling and automated docking of DXL and CTX40, as already described. ${ }^{21}$ In brief, addition of missing hydrogen atoms and computation of the protonation state of ionizable groups in $\beta$-tubulin at $\mathrm{pH} 6.5$ were carried out using the $\mathrm{H}++\mathrm{Web}$ server, ${ }^{36}$ which relies on AMBER force-field parameters ${ }^{37,38}$ and finite difference solutions to the Poisson-Boltzmann equation. The GDP molecule was conserved and the protein side-chains in the nucleotide binding site were slightly reoriented so as to reproduce the same interactions that are observed in the $2.51 \AA$ resolution X-ray crystal structure of $\gamma$-tubulin bound to 5'-guanosinediphosphate-monothio-phosphate ${ }^{39}$ (PDB entry 1Z5V). Following energy minimization, MD simulations at $300 \mathrm{~K}$ were run for these two ligand-protein complexes during $10 \mathrm{~ns}$ under periodic boundary conditions in truncated octahedra each containing $\sim 10,000$ TIP3P water molecules and 11 randomly placed sodium ions to neutralize the total charge of the systems. After this time, the temperature was gradually decreased from $300 \mathrm{~K}$ to $273 \mathrm{~K}$ over $1200 \mathrm{ps}$. Energy minimization of the resulting "cooled" structures employing 5000 cycles of steepest descent followed by 4000 cycles of conjugate gradient provided the "frozen" templates that were used as representative structures to build the remaining complexes for all the CTX derivatives. 
The need for two templates arose from the fact that the $\mathrm{C} 2$ substituent can be placed slightly differently inside the hydrophobic binding pocket, depending on the absence or presence of substituents on the phenyl ring, in such a way that the stacking interaction between the latter and the side chain of His229 is also different. Therefore the bound conformation of DXL was used as the template for model building those taxanes that have no substituent on this ring whereas those bearing bulky substituents on this phenyl were modeled from CTX40. Of note, during the MD simulations we observed the long residence times of two water molecules that bridged a hydrogen bonding interaction between the carbonyl oxygen present in the $\mathrm{C} 2$ linker and the sidechains of Asp226 and His229. Consequently, we decided to keep these two water molecules (WAT1 and WAT2) as part of the ligand-receptor complexes (Figure 3). These two extra residues were later shown to be instrumental for an accurate prediction of taxanes CTX22-27, which have in common the presence of non-ester C2 linkers.

The remaining taxanes bearing modifications on the $\mathrm{C} 2, \mathrm{C} 7, \mathrm{C} 10$ and $\mathrm{C} 13$ substituents were built within the molecular graphics program $\mathrm{PyMOL}^{40}$ using as templates the common baccatin cores of the refined CTX40 and DXL structures in their respective complexes with $\beta$-tubulin. The geometries of the isolated new analogues were fully optimized at the Hartree-Fock level using the Gaussian 03 program ${ }^{41}$ and the $3-21 \mathrm{G}$ basis set. Charge distributions for all the ligands were then obtained by fitting the quantum mechanically calculated $\left(\mathrm{HF} / 6-31 \mathrm{G}^{*} / \mathrm{HF} / 3-21 \mathrm{G}^{*}\right)$ molecular electrostatic potential (MEP) to a RESP point charge model. ${ }^{42}$ Covalent and nonbonded parameters for the inhibitors were derived, by analogy or through interpolation, from those already present in the AMBER ${ }^{37,38}$ database (ff03). The tubulin-taxane complexes were refined by energy minimization using only the steepest descent algorithm in the sander module until the root-mean-square (rms) value of the potential energy gradient was below 0.1 $\mathrm{kcal} \cdot \mathrm{mol}^{-1} \cdot \AA^{-1}$. 
The set of 47 refined ligand-receptor complexes (including WAT1 and WAT2) was then used as input to the gCOMBINE program, ${ }^{25}$ which calculates all the van der Waals (AMBER force field) and electrostatic interaction energies between each ligand and every protein residue. The electrostatic contributions were calculated using Goodford's implementation of the images method $^{43}$ and a uniform dielectric constant of 4.0 Debye. For each complex, the electrostatic contributions to the desolvation energies of both the protein and the ligand, calculated by numerically solving the linear Poisson-Boltzmann equation using the finite difference method as implemented in program DelPhi, ${ }^{44}$ were used as additional descriptors (a.k.a. external variables). ${ }^{24}$ To this end, each complex was centered in a cubic box with a grid spacing of $0.5 \AA$ and a minimum separation of $11 \AA$ was allowed between any solute atom and the box walls. The solute dielectric constant was set to 4 , while the solvent dielectric medium was set to 80 . The dielectric boundary was calculated using a solvent probe radius of $1.4 \AA$. The potentials at the grid points delimiting the box were calculated analytically by treating each charge atom as a Debye-Hückel sphere.

The data matrix containing the computed energy components (X variables) was then subjected to a multivariate statistical analysis using projection to latent structures (a.k.a. partial least squares, PLS $)^{45}$ in order to find a correlation with the experimental binding free energies (Y variable). For cross-validation purposes, a group consisting of 5 randomly chosen complexes was excluded from the training set and used as a test set, as described, ${ }^{25}$ and this procedure was repeated a total of 10 times. This provides a more rigorous estimation of the robustness of the model than the very conservative leave-one-out method. The dimensionality of the model (i.e. the number of extracted latent variables, LV) was chosen as that corresponding to the peak crossvalidated regression coefficient $\left(\mathrm{q}^{2}\right)$ value. 
To study the conformational preferences of these taxanes in aqueous solution, CTX40, CTX42, CTX43 and CTX44 were selected as representative compounds. Each of them was extracted from its respective complex and immersed in a cubic box of approximately 1,400 TIP3P water molecules. Following energy minimization, a 100-ns MD simulation at $300 \mathrm{~K}$ was carried out for each taxane. The resulting trajectories were processed with the ptraj module of AMBER to monitor the rms deviations from the initial T-taxol geometry. Desolvation energies of representative structures of each conformation were obtained using the Generalized Born method that is implemented in the AMBER 10 distribution. The relative energies of each conformer were used to calculate the probability of the microstates $(p)$, as defined by a Boltzmann distribution:

$$
p_{i}=n \mathrm{e}^{-\mathrm{Ei} / \mathrm{RT}} / \Sigma_{\mathrm{j}} n \mathrm{e}^{-\mathrm{Ei} / \mathrm{RT}}
$$

where $n$ is the number of structures belonging to each cluster $i, E_{i}$ is the energy of the average structure extracted from each cluster, $T$ is the temperature in Kelvin, $R$ is the gas constant expressed in $\mathrm{kcal} \cdot \mathrm{mol}^{-1}$ and $j$ is the total number of clusters.

The molecular graphics program PyMOL (v. 0.99rc6, DeLano Scientific, LLC, Palo Alto, $\mathrm{CA})^{28}$ was employed for molecular editing, visualization and representation.

\section{NMR Experiments.}

Samples of MT-bound CTX42 were prepared using a $300 \mu \mathrm{M}$ concentration of CTX42 and 20 $\mu \mathrm{M}$ of tubulin in $\mathrm{D}_{2} \mathrm{O}, 10 \mathrm{mM} \mathrm{KPi}, 0.1 \mathrm{mM}$ GMPCPP, $6 \mathrm{mM} \mathrm{MgCl}_{2} \mathrm{pH}$ 6.7. The tubulin samples were prepared by removing sucrose, $\mathrm{Mg}^{2+}$, and $\mathrm{H}_{2} \mathrm{O}$ from the storage buffer of a $20 \mathrm{mg}$ sample of frozen tubulin using a two-step procedure by chromatography in a drained centrifuge column of Sephadex G-25 medium $(6 \times 1 \mathrm{~cm})$ equilibrated in $\mathrm{D}_{2} \mathrm{O}, 10 \mathrm{mM} \mathrm{KPi}, 10 \mu \mathrm{M}$ GTP pH 7.0 in the cold, followed by a second chromatography using another Sephadex G-25 medium column $(15 \times 0.9 \mathrm{~cm})$ equilibrated in $\mathrm{D}_{2} \mathrm{O}, 10 \mathrm{mM} \mathrm{KPi}, \mathrm{pH}$ 7.0. Tubulin was centrifuged, and its concentration was determined spectrophotometrically by employing an extinction coefficient of 
$107,000 \mathrm{M}^{-1} \mathrm{~cm}^{-1}$ in $10 \mathrm{mM}$ phosphate buffer containing $1 \%$ SDS. Tubulin was diluted to $20 \mu \mathrm{M}$ and GMPCPP $0.1 \mathrm{mM}$ and $6 \mathrm{mM} \mathrm{MgCl}_{2}$ (final $\mathrm{pH}$ 6.7) were added prior to drug incorporation. The samples were then incubated at $37^{\circ} \mathrm{C}$ for 30 min prior to measurement.

The increased solubility of CTX42 relative to the other amide-containing taxanes allowed preparation of a sample of this free compound in the same buffer described above. TR-NOESY information was acquired for CTX42 in the presence of MT with a mixing time of $200 \mathrm{~ms}$ at 310 K. 2D NOE in the rotating frame (ROESY) data were acquired for CTX42 in the free state because the NOESY cross peaks for the free molecule were essentially zero at $310 \mathrm{~K}$. All the spectra were obtained in a Bruker $500 \mathrm{MHz}$ spectrometer.

\section{Synthetic Procedures.}

For C2 modification, the 2-ethyl baccatins were prepared from 10-deacetyl baccatin III (10DAB) by a procedure similar to that described in the literature, ${ }^{42}$ in which the 2-debenzoyl baccatin intermediates were reacted with mesyl chloride and then transformed into the $\mathrm{C} 2$ ethers after treatment with sodium phenolate. Subsequent reduction of the 13-oxo group, incorporation of the C13 side chain bearing the 3 'N-Boc group, and further desilylation led to the final products CTX55 and CTX56.

As it is known that chloroformates derived from tertiary alcohols bearing electron-donating groups (EDGs) are unstable, whereas those bearing electron-withdrawn groups (EWGs) are

relatively stable, ${ }^{46} p$-nitrobenzoyl carbonates were used instead of chloroformates during the carbamoylation of the $3^{\prime}-\mathrm{NH}_{2}$ for some taxanes. For the syntheses of EWG-bearing analogs CTX57, CTX60 and CTX61, the 3'-debenzoyl PXL was transformed into a carbamate by reacting with the corresponding chloroformates, whereas for EDG-bearing 3'N-modified taxanes CTX58 and CTX59, 3'-debenzoyl PXL was transformed into a carbamate by reacting first with 
the corresponding $p$-nitrobenzoyl carbonate,$^{47}$ and then with the corresponding alcohol. By subsequent desilylation the 3'N-modified DXL analogues CTX57 to CTX61 were obtained.

For C3' modifications, the syntheses of the 3'-thiophenyl and 3'-( $m$-hydroxymethyl)phenyl $\beta$ lactams were accomplished as previously reported, ${ }^{48}$ with addition of the Schiff base to the ketene (Staudinger reaction) as the key step. During the synthesis of 3'-benzo[d][1,3]dioxol-5-yl $\beta$-lactam, di-(3,4-methylenedioxybenzaldehyde) substituted Schiff base was applied to Staudinger reaction, and subsequent $\mathrm{N}$-deprotection with $\mathrm{AcOH}$ furnished the $\beta$-lactam. Further kinetic resolution of racemic $\beta$-lactam and incorporation of the Boc group to the $\mathrm{N}$ atom furnished optically active N-Boc- $\beta$-lactam, which was conjugated to 7-triethylsilyl (TES) baccatin III to afford the corresponding 2',7-silyl-protected DXL analogues. Subsequent desilylation furnished 3'-modified taxanes CTX62 to CTX64.

\section{Measurement of the Equilibrium Binding Constants and Cytotoxicity.}

Stabilized, moderately crosslinked MT were prepared from purified calf brain tubulin as reported before. ${ }^{49}$ Binding constants and thermodynamic parameters were measured by displacement of the fluorescent taxane derivative Flutax-2 from the PXL-binding site in these MT. ${ }^{50}$ Wild-type A2780 ovarian carcinoma cells and their P-gp-overexpressing counterparts A2780AD were cultured as described previously. ${ }^{50}$ Cell proliferation was measured using a modified (3-(4,5-dimethylthiazol-2-yl)-2,5-diphenyltetrazolium (MTT) bromide assay, as previously reported. ${ }^{6}$

\section{ACKNOWLEDGEMENTS}


The authors gratefully acknowledge Prof. José Manuel Andreu (CIB, CSIC) for sustained advice, encouragement and useful discussions. C.C. enjoys an FPU grant awarded by the Spanish Ministry of Science and Innovation (AP2007-01225) and A. M. acknowledges Comunidad de Madrid for financial support through the AMAROUTO program to the Fundación Severo Ochoa. This work was financed by the National Natural Science Foundation of China (NSFC grant 30930108 to W.S.F.), the Spanish Ministerio de Ciencia e Innovación (BIO2008-04384 and BIO2010-16351 to F.D.) and Comisión Interministerial de Ciencia y Tecnología (SAF2009-13914C02-02 to F.G.), and Comunidad de Madrid (S-BIO/0214/2006 and S2010-BMD-2457 to F.D. and F.G.). The computer resources, technical expertise and assistance provided by the Barcelona Supercomputing Center (Centro Nacional de Supercomputación) are gratefully acknowledged.

Supporting Information. Supplementary figures, tables and all synthetic procedures are available free of charge via the Internet at http://pubs.acs.org.

\section{References}

1. Schiff, P. B.; Fant, J.; Horwitz, S. B. Promotion of microtubule assembly in vitro by taxol. Nature 1979, 277, 665-667.

2. Breedveld, P.; Beijnen, J. H.; Schellens, J. H. Use of P-glycoprotein and BCRP inhibitors to improve oral bioavailability and CNS penetration of anticancer drugs. Trends Pharmacol. Sci. 2006, 27, 17-24.

3. Ojima, I.; Slater, J. C.; Michaud, E.; Kuduk, S. D.; Bounaud, P. Y.; Vrignaud, P.; Bissery, M. C.; Veith, J. M.; Pera, P.; Bernacki, R. J. Syntheses and structure-activity relationships of the 
second-generation antitumor taxoids: exceptional activity against drug-resistant cancer cells. $J$. Med. Chem. 1996, 39, 3889-3896.

4. Wang, Y. F.; Shi, Q. W.; Dong, M.; Kiyota, H.; Gu, Y. C.; Cong, B. Natural taxanes: developments since 1828. Chem. Rev. 2011.

5. Ojima, I.; Slater, J. C.; Kuduk, S. D.; Takeuchi, C. S.; Gimi, R. H.; Sun, C. M.; Park, Y. H.; Pera, P.; Veith, J. M.; Bernacki, R. J. Syntheses and structure-activity relationships of taxoids derived from 14 beta-hydroxy-10-deacetylbaccatin III. J. Med. Chem. 1997, 40, 267-278.

6. Yang, C. G.; Barasoain, I.; Li, X.; Matesanz, R.; Liu, R.; Sharom, F. J.; Yin, D. L.; Diaz, J. F.; Fang, W. S. Overcoming tumor drug resistance with high-affinity taxanes: a SAR study of C2-modified 7-acyl-10-deacetyl cephalomannines. ChemMedChem 2007, 2, 691-701.

7. Ojima, I.; Chen, J.; Sun, L.; Borella, C. P.; Wang, T.; Miller, M. L.; Lin, S.; Geng, X.; Kuznetsova, L.; Qu, C.; Gallager, D.; Zhao, X.; Zanardi, I.; Xia, S.; Horwitz, S. B.; Mallen-St Clair, J.; Guerriero, J. L.; Bar-Sagi, D.; Veith, J. M.; Pera, P.; Bernacki, R. J. Design, synthesis, and biological evaluation of new-generation taxoids. J. Med. Chem. 2008, 51, 3203-3221.

8. $\quad$ Geney, R.; Sun, L.; Pera, P.; Bernacki, R. J.; Xia, S.; Horwitz, S. B.; Simmerling, C. L.; Ojima, I. Use of the tubulin bound paclitaxel conformation for structure-based rational drug design. Chem. Biol. 2005, 12, 339-348.

9. Suffness, M. Taxol: science and applications. CRC Press: Boca Raton, Florida, 1995; p 426.

10. Nogales, E.; Wolf, S. G.; Downing, K. H. Structure of the alpha beta tubulin dimer by electron crystallography. Nature 1998, 391, 199-203.

11. Lowe, J.; Li, H.; Downing, K. H.; Nogales, E. Refined structure of alpha beta-tubulin at 3.5 A resolution. J. Mol. Biol. 2001, 313, 1045-1057. 
12. Sun, L.; Simmerling, C.; Ojima, I. Recent advances in the study of the bioactive conformation of taxol. ChemMedChem 2009, 4, 719-731.

13. Forli, S.; Manetti, F.; Altmann, K. H.; Botta, M. Evaluation of novel epothilone analogues by means of a common pharmacophore and a QSAR pseudoreceptor model for taxanes and epothilones. ChemMedChem 2010, 5, 35-40.

14. Snyder, J. P.; Nettles, J. H.; Cornett, B.; Downing, K. H.; Nogales, E. The binding conformation of Taxol in beta-tubulin: a model based on electron crystallographic density. Proc. Natl. Acad. Sci. USA 2001, 98, 5312-5316.

15. Kingston, D. G.; Bane, S.; Snyder, J. P. The taxol pharmacophore and the T-taxol bridging principle. Cell Cycle 2005, 4, 279-289.

16. Alcaraz, A. A.; Mehta, A. K.; Johnson, S. A.; Snyder, J. P. The T-Taxol conformation. J. Med. Chem. 2006, 49, 2478-2488.

17. Walters, W. P.; Green, J.; Weiss, J. R.; Murcko, M. A. What do medicinal chemists actually make? A 50-year retrospective. J. Med. Chem. 2011, 54, 6405-6416.

18. Ojima, I.; Chakravarty, S.; Inoue, T.; Lin, S.; He, L.; Horwitz, S. B.; Kuduk, S. D.; Danishefsky, S. J. A common pharmacophore for cytotoxic natural products that stabilize microtubules. Proc. Natl. Acad. Sci. USA 1999, 96, 4256-4261.

19. Ojima, I.; Das, M. Recent advances in the chemistry and biology of new generation taxoids. J. Nat. Prod. 2009, 72, 554-565.

20. Ganesh, T.; Yang, C.; Norris, A.; Glass, T.; Bane, S.; Ravindra, R.; Banerjee, A.; Metaferia, B.; Thomas, S. L.; Giannakakou, P.; Alcaraz, A. A.; Lakdawala, A. S.; Snyder, J. P.; Kingston, D. G. Evaluation of the tubulin-bound paclitaxel conformation: synthesis, biology, and SAR studies of C-4 to C-3' bridged paclitaxel analogues. J. Med. Chem. 2007, 50, 713-725. 
21. Matesanz, R.; Barasoain, I.; Yang, C. G.; Wang, L.; Li, X.; de Ines, C.; Coderch, C.; Gago, F.; Barbero, J. J.; Andreu, J. M.; Fang, W. S.; Diaz, J. F. Optimization of taxane binding to microtubules: binding affinity dissection and incremental construction of a high-affinity analog of paclitaxel. Chem. Biol. 2008, 15, 573-585.

22. Singh, N.; Warshel, A. A comprehensive examination of the contributions to the binding entropy of protein-ligand complexes. Proteins 2010, 78, 1724-1735.

23. Coderch, C. K., J.; Morreale, A.; Díaz, J.-F.; Gago, F. Comparative Binding Energy (COMBINE) analysis supports a proposal for the binding mode of epothilones to $\beta$-tubulin. ChemMedChem 2012, 7, 836-843.

24. Perez, C.; Pastor, M.; Ortiz, A. R.; Gago, F. Comparative binding energy analysis of HIV1 protease inhibitors: incorporation of solvent effects and validation as a powerful tool in receptor-based drug design. J. Med. Chem. 1998, 41, 836-852.

25. Gil-Redondo, R.; Klett, J.; Gago, F.; Morreale, A. gCOMBINE: A graphical user interface to perform structure-based comparative binding energy (COMBINE) analysis on a set of ligand-receptor complexes. Proteins 2010, 78, 162-172.

26. Reese, M.; Sanchez-Pedregal, V. M.; Kubicek, K.; Meiler, J.; Blommers, M. J.; Griesinger, C.; Carlomagno, T. Structural basis of the activity of the microtubule-stabilizing agent epothilone A studied by NMR spectroscopy in solution. Angew. Chem. Int. Ed. Engl. 2007, 46, 1864-1868.

27. Wang, L.; Alcaraz, A. A.; Matesanz, R.; Yang, C. G.; Barasoain, I.; Diaz, J. F.; Li, Y. Z.; Snyder, J. P.; Fang, W. S. Synthesis, biological evaluations, and tubulin binding poses of C2alpha sulfur linked taxol analogues. Bioorg. Med. Chem. Lett. 2007, 17, 3191-3194. 
28. Rodriguez-Barrios, F.; Gago, F. Chemometrical identification of mutations in HIV-1 reverse transcriptase conferring resistance or enhanced sensitivity to arylsulfonylbenzonitriles. $J$. Am. Chem. Soc. 2004, 126, 2718-2719.

29. Freedman, H.; Huzil, J. T.; Luchko, T.; Luduena, R. F.; Tuszynski, J. A. Identification and characterization of an intermediate taxol binding site within microtubule nanopores and a mechanism for tubulin isotype binding selectivity. J. Chem. Inf. Model. 2009, 49, 424-436.

30. Ferlini, C.; Raspaglio, G.; Mozzetti, S.; Cicchillitti, L.; Filippetti, F.; Gallo, D.; Fattorusso, C.; Campiani, G.; Scambia, G. The seco-taxane IDN5390 is able to target class III beta-tubulin and to overcome paclitaxel resistance. Cancer Res. 2005, 65, 2397-2405.

31. Snyder, P. W.; Mecinovic, J.; Moustakas, D. T.; Thomas, S. W., 3rd; Harder, M.; Mack, E. T.; Lockett, M. R.; Heroux, A.; Sherman, W.; Whitesides, G. M. Mechanism of the hydrophobic effect in the biomolecular recognition of arylsulfonamides by carbonic anhydrase. Proc. Natl. Acad. Sci. USA 2011, 108, 17889-17894.

32. Williams, D. H.; Cox, J. P. L.; Doig, A. J.; Gardner, M.; Gerhard, U.; Kaye, P. T.; Lal, A. R.; Nicholls, I. A.; Salter, C. J.; Mitchell, R. C. Toward the semiquantitative estimation of binding constants. Guides for peptide-peptide binding in aqueous solution. J. Am. Chem. Soc. 1991, 113, 7020-7030.

33. Todd, M. J.; Luque, I.; Velazquez-Campoy, A.; Freire, E. Thermodynamic basis of resistance to HIV-1 protease inhibition: calorimetric analysis of the V82F/I84V active site resistant mutant. Biochemistry 2000, 39, 11876-11883.

34. Marshall, G. R. Limiting assumptions in structure-based design: binding entropy. $J$. Comput.-Aided Mol. Des. 2012, 26, 3-8.

35. Luque, I.; Todd, M. J.; Gomez, J.; Semo, N.; Freire, E. Molecular basis of resistance to HIV-1 protease inhibition: a plausible hypothesis. Biochemistry 1998, 37, 5791-5797. 
36. Gordon, J. C.; Myers, J. B.; Folta, T.; Shoja, V.; Heath, L. S.; Onufriev, A. H++: a server for estimating pKas and adding missing hydrogens to macromolecules. Nucleic Acids Res. 2005, 33, W368-371.

37. Cornell, W. D.; Cieplak, P.; Bayly, C. I.; Gould, I. R.; Merz, K. M.; Ferguson, D. M.; Spellmeyer, D. C.; Fox, T.; Caldwell, J. W.; Kollman, P. A. A Second Generation Force Field for the Simulation of Proteins, Nucleic Acids, and Organic Molecules. J. Am. Chem. Soc. 1995, 117, $5179-5197$.

38. Cornell, W. D.; Cieplak, P.; Bayly, C. I.; Gould, I. R.; Merz, K. M.; Ferguson, D. M.; Spellmeyer, D. C.; Fox, T.; Caldwell, J. W.; Kollman, P. A. A second generation force field for the simulation of proteins, nucleic acids, and organic molecules. J. Am. Chem. Soc. 1996, 118, 2309-2309.

39. Aldaz, H.; Rice, L. M.; Stearns, T.; Agard, D. A. Insights into microtubule nucleation from the crystal structure of human gamma-tubulin. Nature 2005, 435, 523-527.

40. Zhang, Y.; Simpson, A. A.; Ledford, R. M.; Bator, C. M.; Chakravarty, S.; Skochko, G. A.; Demenczuk, T. M.; Watanyar, A.; Pevear, D. C.; Rossmann, M. G. Structural and virological studies of the stages of virus replication that are affected by antirhinovirus compounds. J. Virol. 2004, 78, 11061-11069.

41. Frisch, M. J.; Trucks, G. W.; Schlegel, H. B.; Scuseria, G. E.; Robb, M. A.; Cheeseman, J. R.; Montgomery, J. A.; Vreven, T.; Kudin, K. N.; Burant, J. C.; Millam, J. M.; Iyengar, S. S.; Tomasi, J.; Barone, V.; Mennucci, B.; Cossi, M.; Scalmani, G.; Rega, N.; Petersson, G. A.; Nakatsuji, H.; Hada, M.; Ehara, M.; Toyota, K.; Fukuda, R.; Hasegawa, J.; Ishida, M.; Nakajima, T.; Honda, Y.; Kitao, O.; Nakai, H.; Klene, M.; Li, X.; Knox, J. E.; Hratchian, H. P.; Cross, J. B.; Bakken, V.; Adamo, C.; Jaramillo, J.; Gomperts, R.; Stratmann, R. E.; Yazyev, O.; Austin, A. J.; Cammi, R.; Pomelli, C.; Ochterski, J. W.; Ayala, P. Y.; Morokuma, K.; Voth, G. A.; Salvador, 
P.; Dannenberg, J. J.; Zakrzewski, V. G.; Dapprich, S.; Daniels, A. D.; Strain, M. C.; Farkas, O.; Malick, D. K.; Rabuck, A. D.; Raghavachari, K.; Foresman, J. B.; Ortiz, J. V.; Cui, Q.; Baboul, A. G.; Clifford, S.; Cioslowski, J.; Stefanov, B. B.; Liu, G.; Liashenko, A.; Piskorz, P.; Komaromi, I.; Martin, R. L.; Fox, D. J.; Keith, T.; Laham, A.; Peng, C. Y.; Nanayakkara, A.; Challacombe, M.; Gill, P. M. W.; Johnson, B.; Chen, W.; Wong, M. W.; Gonzalez, C.; Pople, J. A. Gaussian 03, Revision B.04. In Gaussian, Inc.: Pittsburgh, PA., 2003.

42. Bayly, C. I.; Cieplak, P.; Cornell, W.; Kollman, P. A. A well-behaved electrostatic potential based method using charge restraints for deriving atomic charges: the RESP model. Journal of Physical Chemistry 1993, 97, 10269-10280.

43. Goodford, P. J. A computational procedure for determining energetically favorable binding sites on biologically important macromolecules. J. Med. Chem. 1985, 28, 849-857.

44. Nicholls, A.; Honig, B. A rapid finite difference algorithm, utilizing successive overrelaxation to solve the Poisson-Boltzmann equation. J. Comput. Chem. 1991, 12, 435-445.

45. Abdi, H. Partial least squares regression and projection on latent structure regression (PLS Regression). Wiley Interdisciplinary Reviews: Computational Statistics 2010, 2, 97-106.

46. Simila, S. T. M.; Martin, S. F. Toward the Total Synthesis of FR901483: Concise Synthesis of the Azatricyclic Skeleton. J. Org. Chem. 2007, 72, 5342-5349.

47. Bertrand, P.; Gesson, J. P. Click Chemistry with O-Dimethylpropargylcarbamate for Preparation of pH-Sensitive Functional Groups. A Case Study. J. Org. Chem. 2007, 72, 35963599.

48. Brieva, R.; Crich, J. Z.; Sih, C. J. Chemoenzymic synthesis of the C-13 side chain of taxol: optically active 3-hydroxy-4-phenyl $\beta$-lactam derivatives. J. Org. Chem. 1993, 58, 1068 1075. 
49. Diaz, J. F.; Barasoain, I.; Andreu, J. M. Fast kinetics of Taxol binding to microtubules. Effects of solution variables and microtubule-associated proteins. J. Biol. Chem. 2003, 278, 8407-8419.

50. Buey, R. M.; Barasoain, I.; Jackson, E.; Meyer, A.; Giannakakou, P.; Paterson, I.; Mooberry, S.; Andreu, J. M.; Diaz, J. F. Microtubule interactions with chemically diverse stabilizing agents: thermodynamics of binding to the paclitaxel site predicts cytotoxicity. Chem. Biol. 2005, 12, 1269-1279. 


\section{FIGURES}

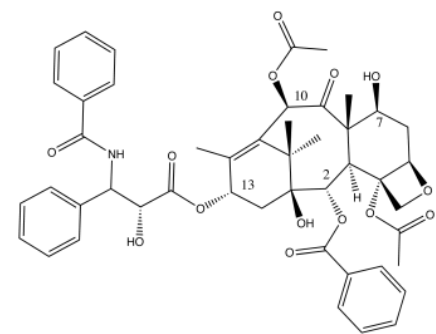

PXL

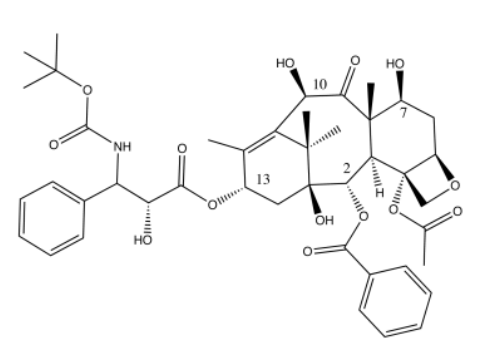

DXL

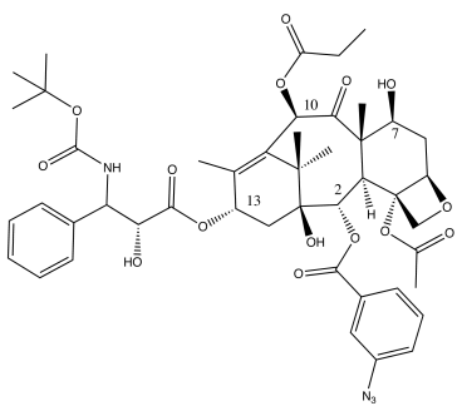

CTX40

Figure 1. Chemical structures of paclitaxel (PXL), docetaxel (DXL) and CTX40. 


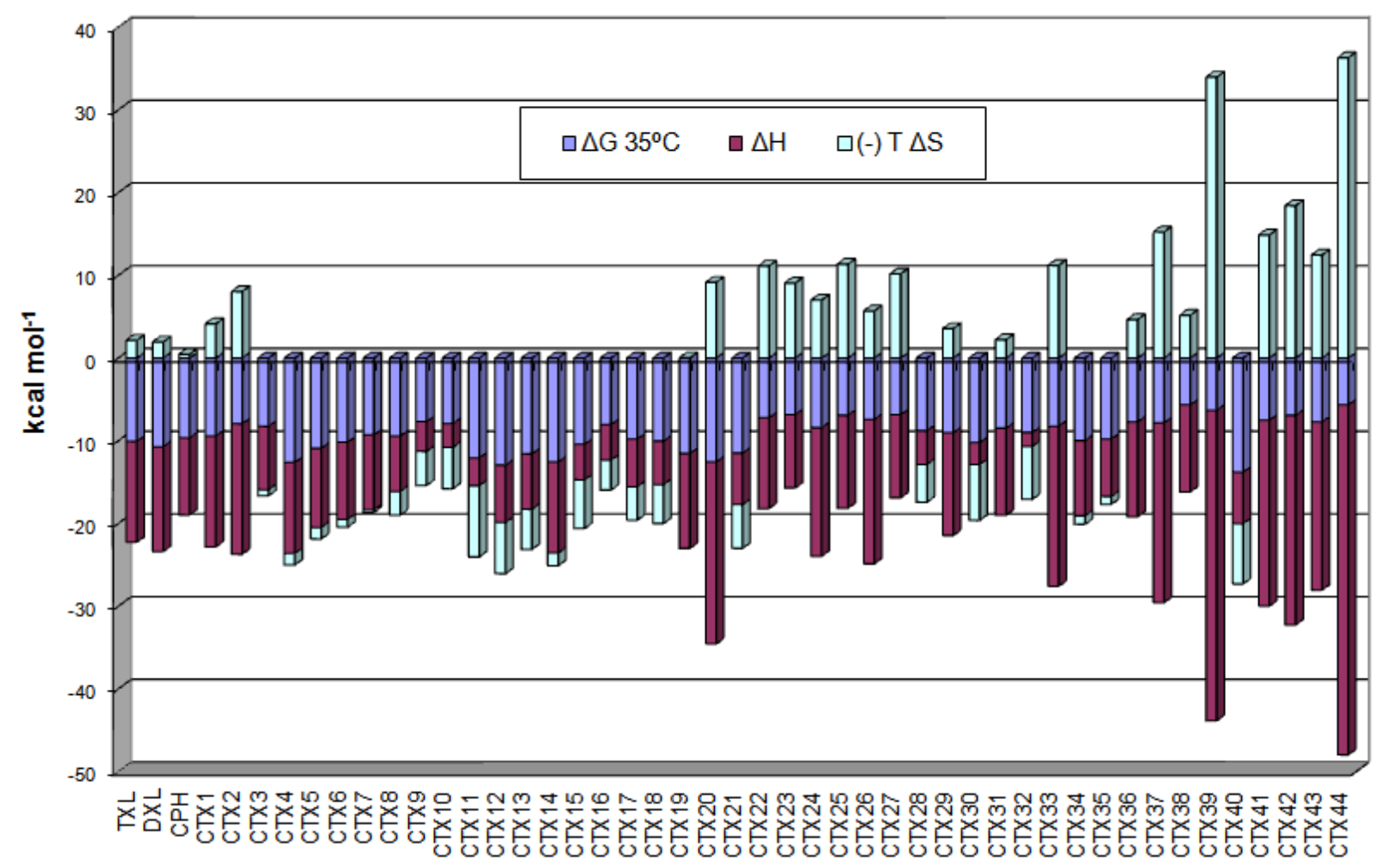

Figure 2. Thermodynamic parameters $\left(\mathrm{kcal} \cdot \mathrm{mol}^{-1}\right)$ for the binding of the taxanes studied to the PXL site in bovine $\beta$-tubulin, as reported in Table 1 of reference 21 . Note that actual values correspond only to the length of the colored block, i.e. are not cumulative. 


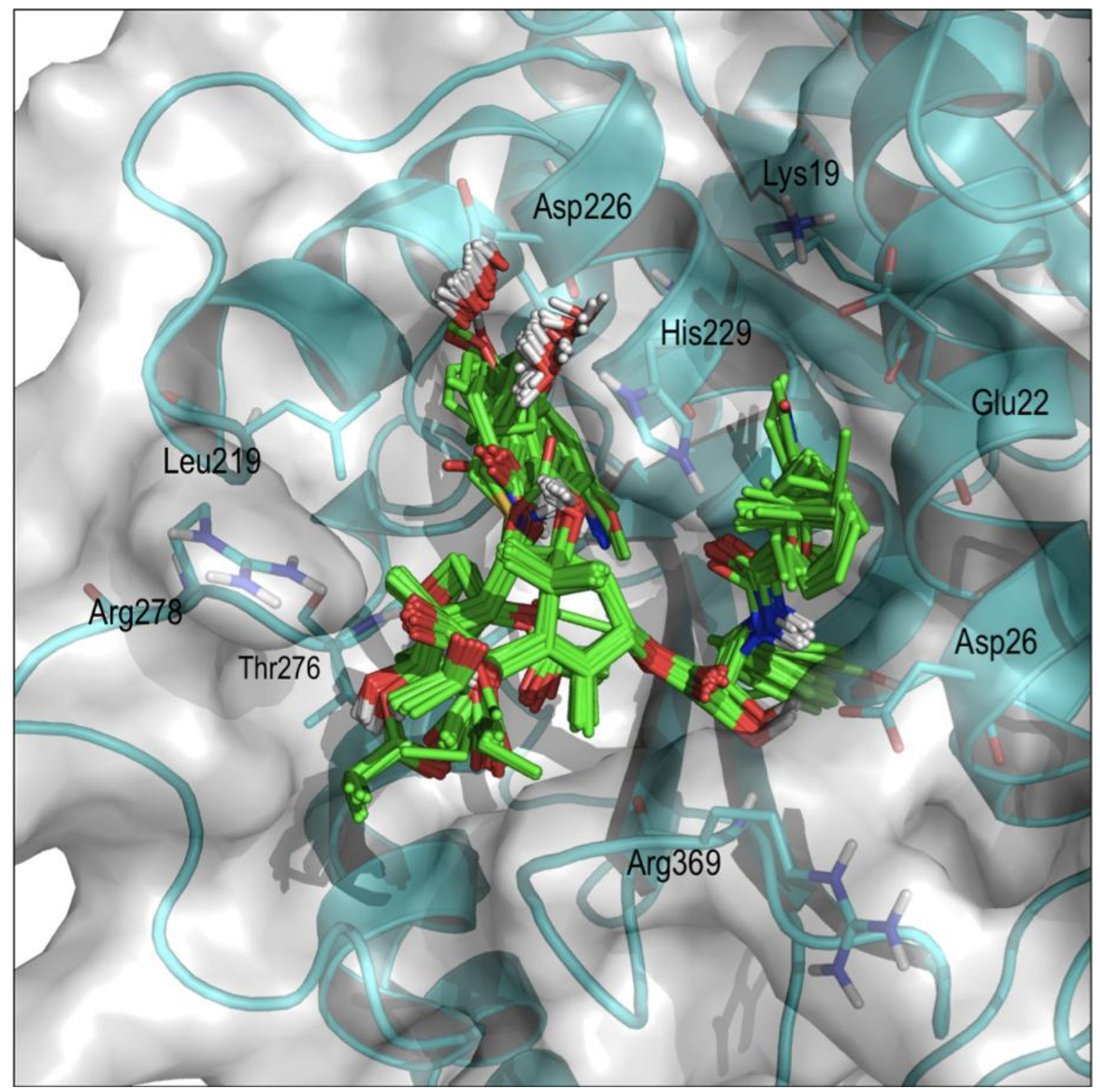

Figure 3. Superposition of the set of taxanes studied inside the PXL-binding site of $\beta$-tubulin. For simplicity, only the cartoon representation of the protein (from the DXL-tubulin complex) enveloped by a semitransparent grey van der Waals surface is shown. 


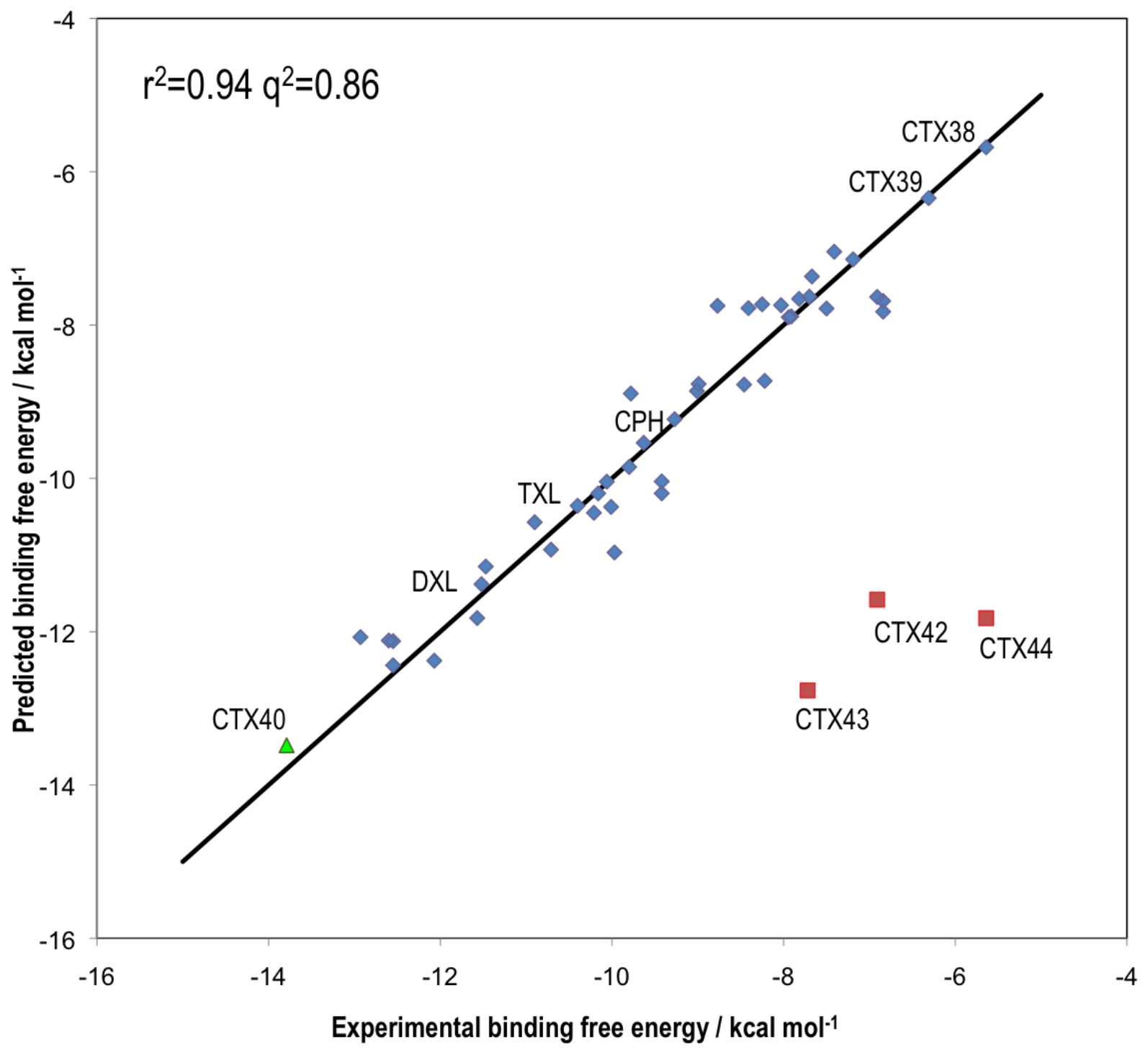

Figure 4. Correlation between the binding free energies calculated in the cross-validated COMBINE model and the experimental values for compounds in the training set $(\diamond)$ upon exclusion of the three outliers ( $\square$ ). This model, with only $5 \mathrm{LV}$, accurately predicts the affinity of CTX40 ( $\bullet$ ), which was not included in model derivation. 


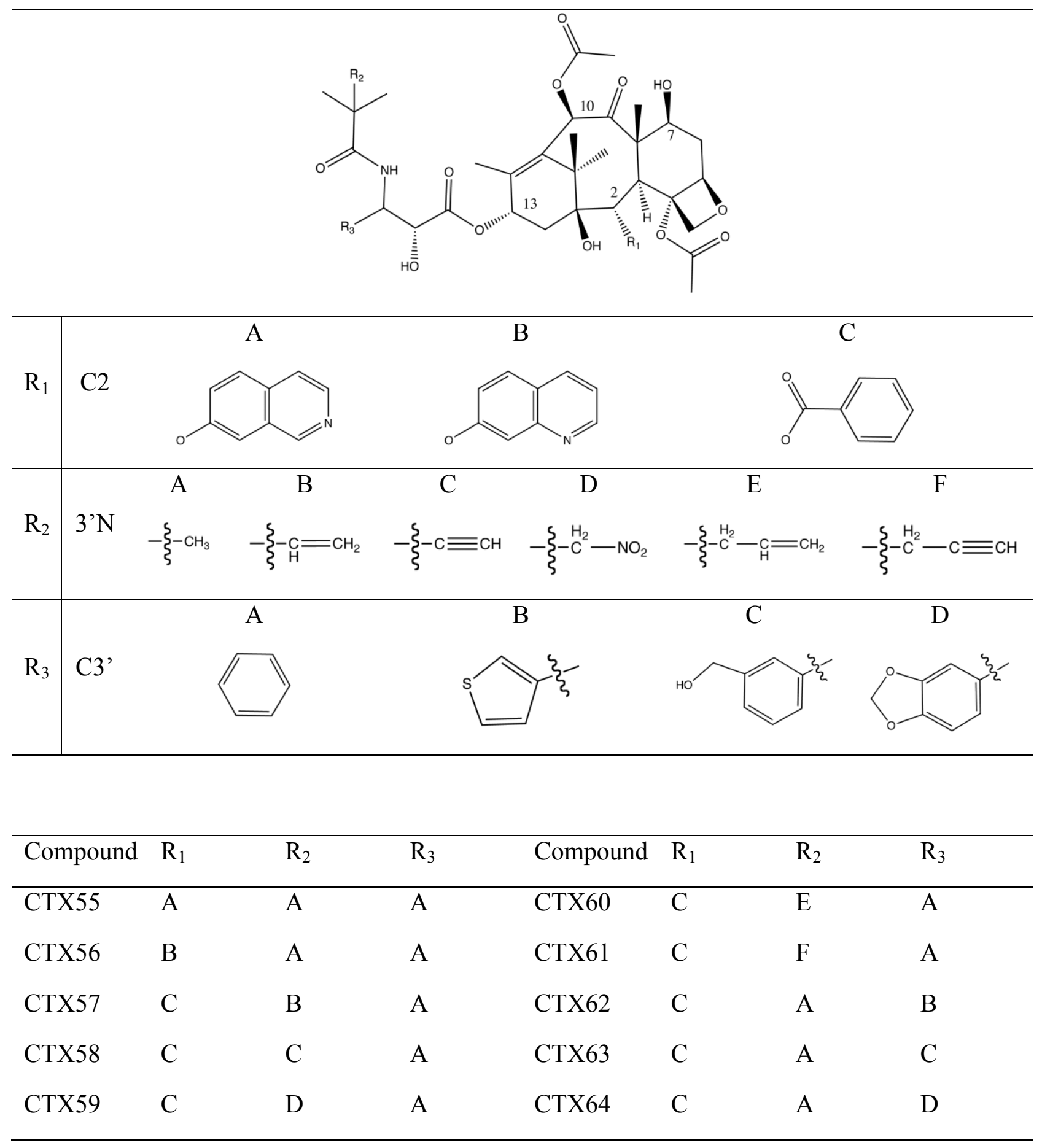

Figure 5. Novel taxanes incorporating modifications at positions $\mathrm{C} 2$ and $\mathrm{C} 3$ ' and 3 'N. 


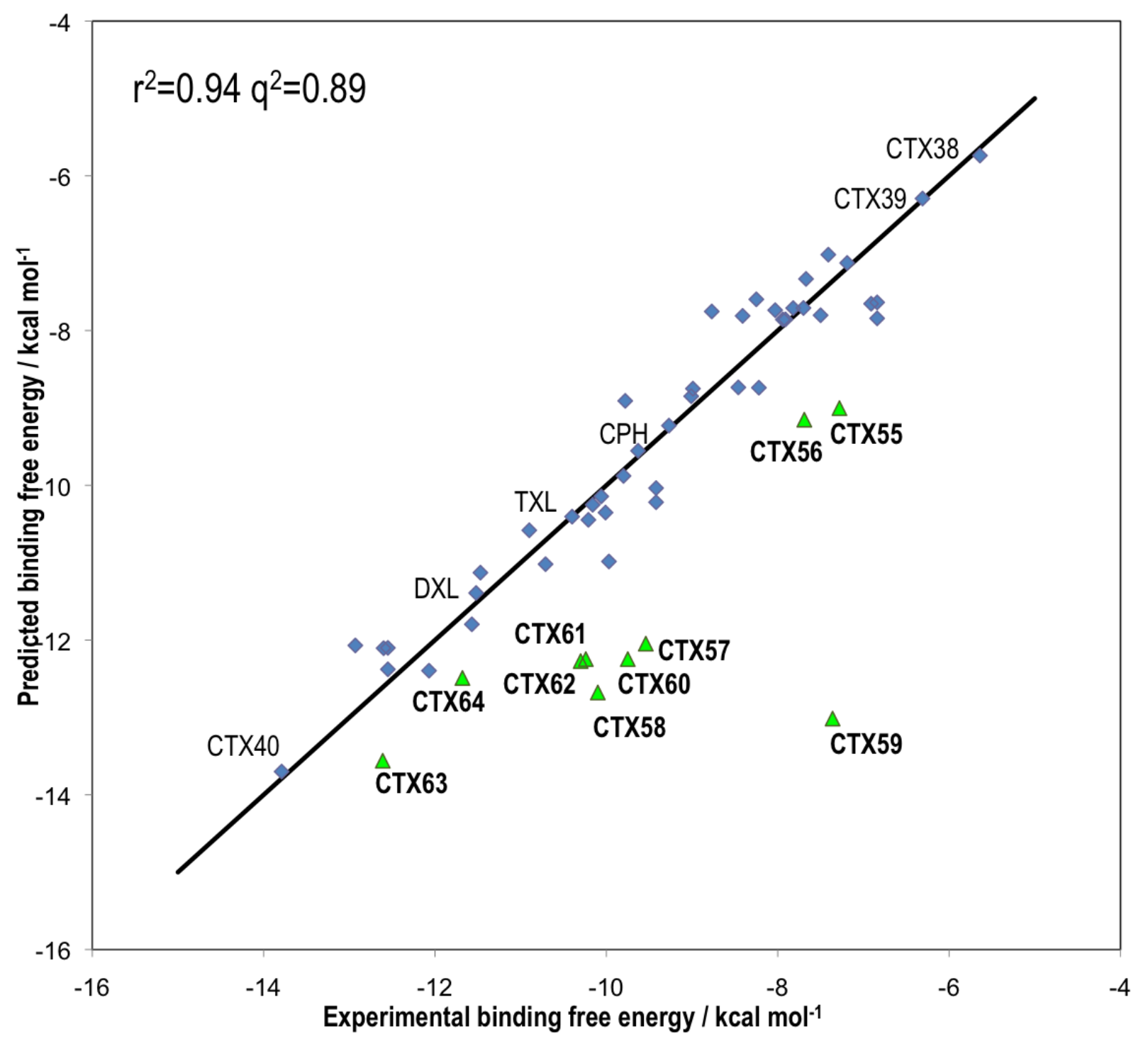

Figure 6. Correlation between the binding free energies calculated in the cross-validated COMBINE model (5 LV) and the experimental values for compounds in the training set $(\diamond)$ and for the external set consisting of the newly synthesized taxanes $(\Delta)$. 


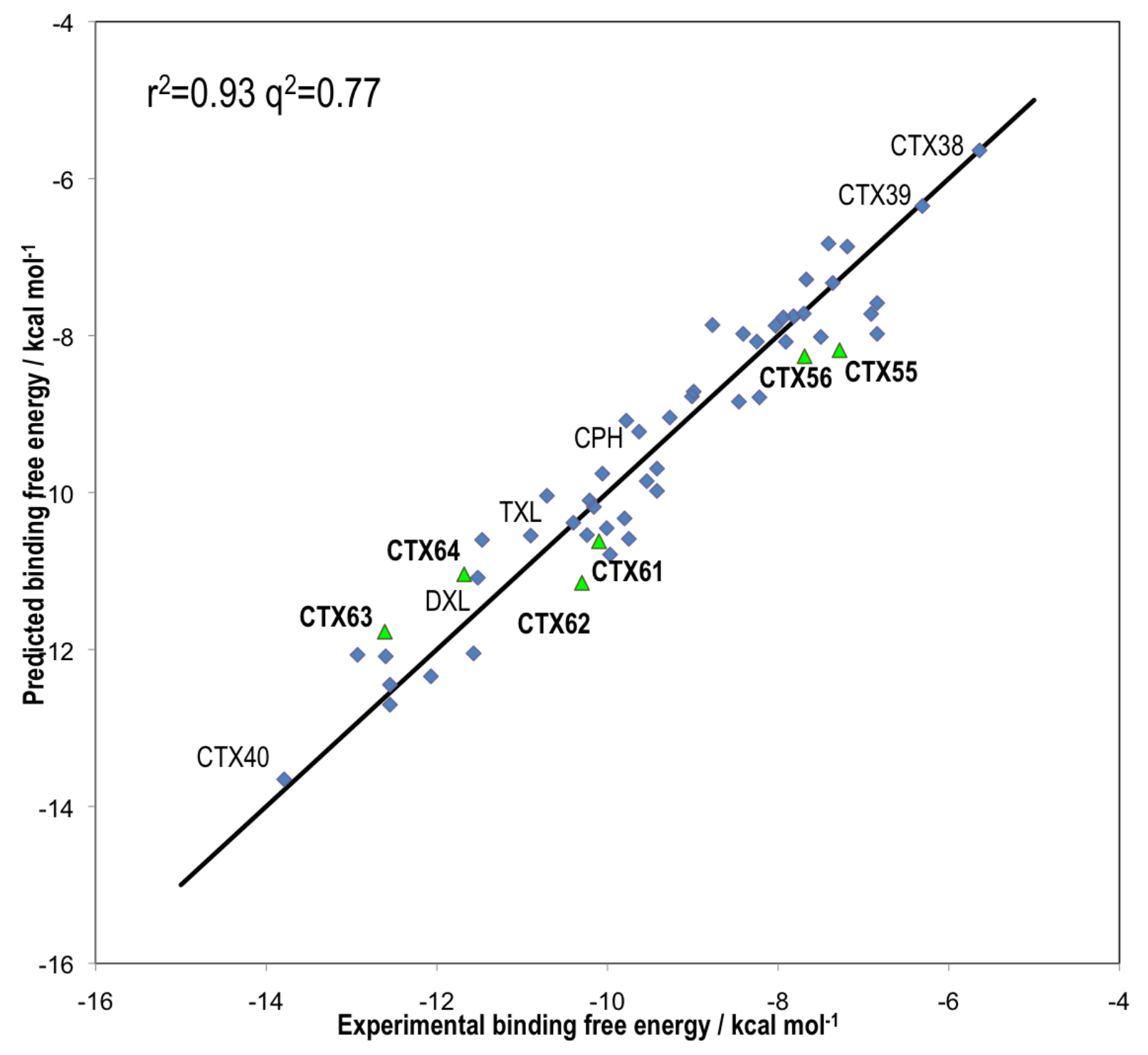

Figure 7. Correlation between calculated and experimental binding free energies in the updated COMBINE model that now includes in the training set $(\diamond)$ the $3^{\prime} \mathrm{N}$-substituted derivatives CTX57 to CTX60 and correctly predicts the external set $(\Delta)$ consisting of the fourth $3^{\prime} \mathrm{N}$ derivative CTX61, the new C2-substituted taxanes CTX55 and CTX56, and the C3'-substituted analogs CTX62 to CTX64. 


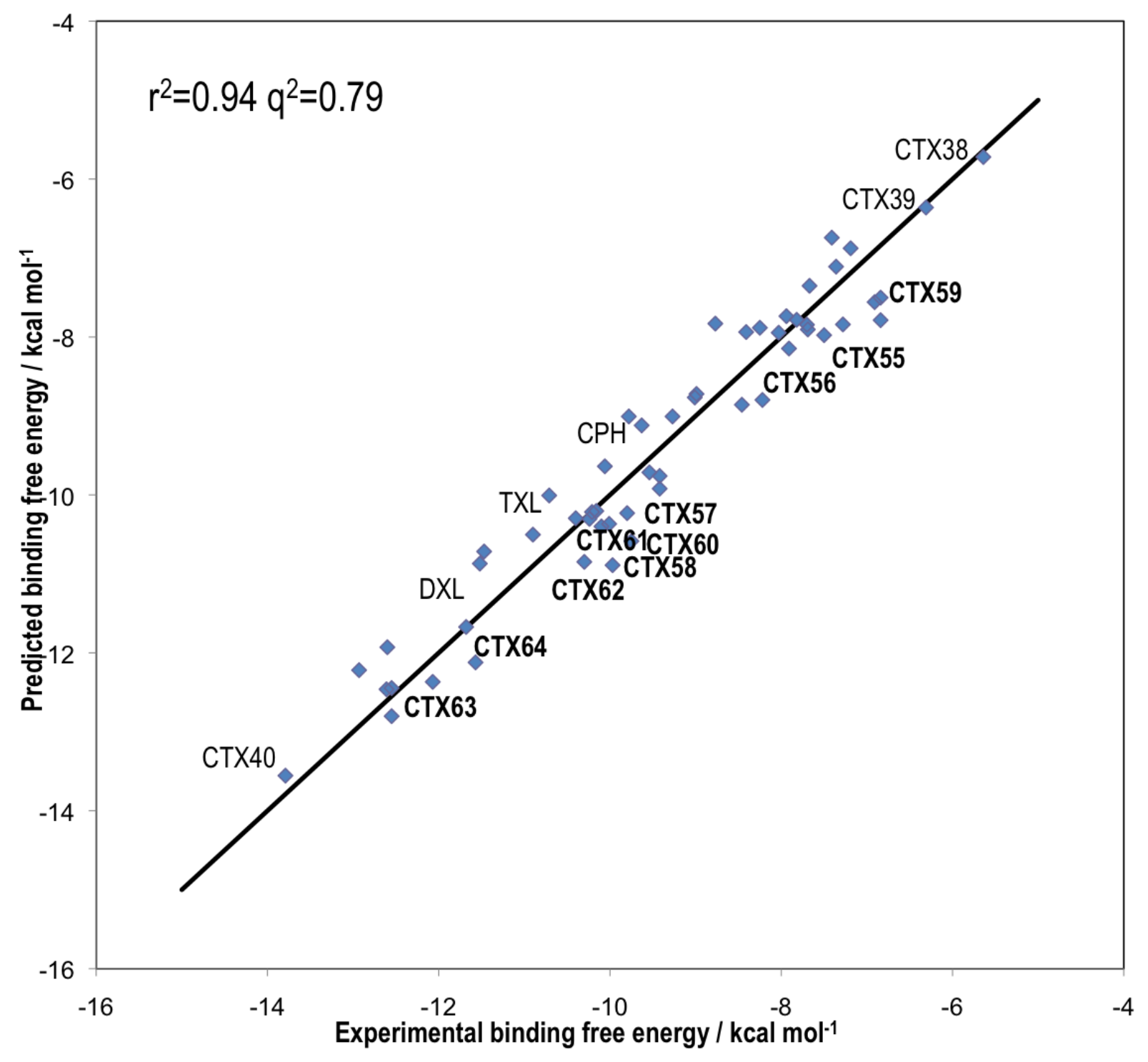

Figure 8. Updated COMBINE model $(7 \mathrm{LV})$ that includes all the studied taxanes in the training set $(\diamond)$. 


\section{TABLES}

Table 1. Selected PLS pseudocoefficients (absolute value $\geq|0.1|$ ) for the energy terms that contribute the most to explaining the predicted binding free energy differences in the COMBINE model used to predict the novel taxanes.

\begin{tabular}{lcccccc}
\hline Residue & vdW & Ele & & Residue & vdW & Ele \\
\cline { 1 - 1 } \cline { 5 - 6 } Lys19 & & 0.11 & & Phe272 & 0.60 & \\
Glu22 & -0.1 & 0.16 & & Pro274 & 0.1 & \\
Va123 & 0.15 & & & Leu275 & 0.24 & \\
Asp26 & 0.30 & & & Thr276 & -0.1 & 0.1 \\
Glu27 & & 0.14 & & Arg278 & & 0.31 \\
Cys213 & -0.21 & & & Gln282 & -0.1 & 0.1 \\
Leu217 & -0.33 & & & Pro360 & 0.1 & -0.1 \\
Leu219 & -0.26 & & & Arg369 & 0.1 & \\
Asp226 & 0.25 & -0.49 & & Gly370 & -0.23 & -0.15 \\
Hip229 & 0.55 & 0.50 & & WAT2 & -0.52 & 0.62 \\
Leu230 & 0.14 & & & & \\
Ala233 & 0.48 & & & DesolvL & & -0.16 \\
\hline
\end{tabular}


Table 2. Selected PLS pseudocoefficients (absolute value $\geq|0.1|$ ) for the amino acid residues that contribute the most to explaining the predicted binding free energy differences in the model after introducing $3^{\prime} \mathrm{N}$ modifications in the training set.

\begin{tabular}{|c|c|c|c|c|c|}
\hline Residue & $\mathrm{vdW}$ & Ele & Residue & $\mathrm{vdW}$ & Ele \\
\hline Lys19 & -0.70 & -0.68 & Pro274 & 0.18 & \\
\hline Glu22 & -0.97 & 0.28 & Leu 275 & 0.45 & -0.1 \\
\hline Val23 & 0.45 & -0.1 & Thr276 & & 0.20 \\
\hline Asp26 & 0.1 & & Ser277 & 0.19 & 0.16 \\
\hline Glu27 & 0.22 & 0.12 & Arg 278 & -0.23 & 0.36 \\
\hline Cys 213 & -0.18 & & Gln 282 & -0.20 & 0.20 \\
\hline Leu217 & -0.41 & & Arg320 & -0.23 & \\
\hline Leu219 & -0.31 & & Pro360 & 0.1 & \\
\hline Asp226 & 0.20 & -0.46 & Arg369 & -0.10 & 0.36 \\
\hline His229 & 0.43 & 0.61 & Gly370 & -0.49 & -0.25 \\
\hline Leu230 & 0.12 & & WAT1 & & 0.19 \\
\hline Ala233 & 0.55 & & WAT2 & -0.27 & 0.38 \\
\hline Gly237 & -0.14 & -0.14 & DesolvR & & 0.1 \\
\hline Phe272 & 0.94 & & DesolvL & & -0.2 \\
\hline
\end{tabular}


Table 3. Selected PLS pseudocoefficients (absolute value $\geq|0.1|$ ) for the amino acid residues that contribute the most to explaining the predicted binding free energy differences in the final updated COMBINE model.

\begin{tabular}{|c|c|c|c|c|c|}
\hline Residue & $\mathrm{vdW}$ & Ele & Residue & $\mathrm{vdW}$ & Ele \\
\hline Lys19 & $\begin{array}{l}-0.72 \\
\end{array}$ & -0.67 & Pro274 & 0.20 & \\
\hline Glu22 & -1.02 & 0.25 & Leu275 & 0.46 & -0.10 \\
\hline Val23 & 0.45 & & Thr276 & -0.1 & 0.24 \\
\hline Asp26 & & -0.1 & Ser277 & 0.21 & 0.18 \\
\hline Glu27 & 0.25 & 0.26 & $\operatorname{Arg} 278$ & -0.22 & 0.35 \\
\hline Cys213 & -0.15 & & $\mathrm{G} \ln 282$ & -0.18 & 0.22 \\
\hline Leu217 & -0.48 & & Pro360 & 0.34 & \\
\hline Leu219 & -0.33 & & Arg369 & -0.20 & 0.46 \\
\hline Asp226 & 0.12 & -0.48 & Gly370 & -0.48 & -0.23 \\
\hline His229 & 0.42 & 0.54 & WAT1 & & 0.17 \\
\hline Leu230 & 0.16 & & WAT2 & -0.32 & 0.46 \\
\hline Ala233 & 0.64 & -0.21 & DesolvR & & 0.12 \\
\hline Phe272 & 0.89 & & DesolvL & & -0.27 \\
\hline
\end{tabular}

